ISSN 1029-8940 (Print)

ISSN 2524-230X (Online)

УДК 579.6; 57.046

https://doi.org/10.29235/1029-8940-2019-64-1-96-101

Поступила в редакцию 14.11.2018

Received 14.11.2018

\title{
А. А. Арашкова
}

Институт микробиологии НАН Беларуси, Минск, Республика Беларусь

\section{ГРИБОСТОЙКОСТЬ СТРОИТЕЛЬНЫХ БЛОКОВ В УСЛОВИЯХ МОДЕЛЬНОГО ЭКСПЕРИМЕНТА}

\begin{abstract}
Аннотация. Испытания грибостойкости строительных блоков проведены путем модельного заражения материалов грибным мицелием и спорами. Установлено, что риск развития плесневых грибов на газосиликатных блоках во влажной среде эксплуатации выше, чем на керамзитобетонных блоках. Профилактика плесневого поражения сооружений из ячеистого и керамзитобетона должна включать предотвращение избыточного увлажнения и органического загрязнения, способствующих развитию биодеструкторов.

Ключевые слова: испытания на грибостойкость, микробиологическая стойкость материалов, биоповреждение, плесневые грибы

Для цитирования: Арашкова, А. А. Грибостойкость строительных блоков в условиях модельного эксперимента / А. А. Арашкова // Вес. Нац. акад. навук Беларусі. Сер. біял. навук. - 2019. - Т. 64, № 1. - С. 96-101. https://doi. org/10.29235/1029-8940-2019-64-1-96-101
\end{abstract}

\section{A. A. Arashkova}

Institute of Microbiology of the National Academy of Sciences of Belarus, Minsk, Republic of Belarus

\section{MOULD RESISTANCE OF BUILDING BLOCKS IN THE CONDITIONS OF MODEL EXPERIMENT}

Abstract. Mould resistance testing of concrete building blocks was carried out by model contamination of materials by fungal mycelium and spores. It has been established that the risk of development of mould fungi on gas silicate blocks in humid environment is higher than on claydite-concrete blocks. At the same time, the prevention of mould damage of concrete buildings should include prevention of excessive moisture and organic contamination that contribute to the development of biodestructors.

Keywords: mould resistance testing, microbiological resistance of materials, biodegradation, mould fungi

For citation: Arashkova A. A. Mould resistance of building blocks in the conditions of model experiment. Vestsi Natsyyanal'nai akademii navuk Belarusi. Seryya biyalagichnych navuk = Proceedings of the National Academy of Sciences of Belarus. Biological series, 2019, vol. 64, no. 1, pp. 96-101 (in Russian). https://doi.org/10.29235/1029-8940-2019-64-196-101

Введение. Очаги плесневого поражения зданий и сооружений возникают из-за протечек кровли, проникновения влаги через стены и фундамент при нарушениях гидроизоляции и системы наружного водоотведения. Действие микробиологического фактора может существенно сокращать срок эксплуатации строительных конструкций и приводить к их преждевременному разрушению [1], а продукты биодеструкции и жизнедеятельности плесневых грибов могут быть токсичны и аллергенны для человека [2].

В естественных условиях попадание микроскопических грибов (микромицетов) на строительные конструкции происходит посредством переноса спор и фрагментов мицелия воздушными потоками, почвенными и дождевыми водами, насекомыми, а также в результате загрязнения поверхностей [3]. Благоприятные условия влажности в сочетании с подверженностью строительного материала к биодеструкции приводят к развитию микромицетов на поверхности материалов и последующему проникновению их вглубь [4].

Проблема плесневого поражения зданий, как правило, неотъемлемый признак старых построек. Однако в последние годы отмечают распространение процессов биоповреждения на современные здания, а также увеличение видового разнообразия грибов - биодеструкторов новых строительных материалов $[5,6]$.

(C) Арашкова А. А., 2019 
Надежность конструкций в условиях эксплуатации во многом определяется стойкостью строительных материалов к воздействию коррозионно-агрессивных факторов внешней среды, естественной составляющей которых являются микроскопические плесневые грибы. В связи с этим одной из важных задач при планировании и осуществлении защиты зданий и сооружений от биологического повреждения является оценка и прогноз грибостойкости материалов, используемых при строительстве и реконструкции [7].

Для детальной оценки грибостойкости строительных материалов необходим комплексный подход с использованием методов и стандартов, учитывающих специфику материала и моделирующих благоприятные условия для его колонизации плесневыми грибами, включая температурно-влажностный режим и поверхностное загрязнение [8].

Цель данного исследования - испытание строительных газосиликатных и керамзитобетонных блоков на грибостойкость путем моделирования контакта материалов со спорами и мицелием плесневых грибов.

Объекты и методы исследования. Для микологических испытаний использовали образцы строительных блоков $(6,0 \times 6,0 \times 1,5$ см) из ячеистого бетона (газосиликат) и керамзитобетона («ТермоКомфорт»), предварительно не подвергавшиеся климатическим и механическим воздействиям (рис. 1).

Исходная влажность образцов газосиликатных блоков составляла 30 \%, керамзитобетонных 7 \%. Для проведения испытаний образцы погружали в воду и выдерживали до полного их влагонасыщения. Для моделирования локального увеличения влажности материалов на поверхность образцов помещали диски $(d=1 \mathrm{~cm})$, высверленные из застывшей агаризованной среды, содержащей 1,5 \% агар-агара. Предварительно диски инокулировали спорами гриба Aspergillus niger.

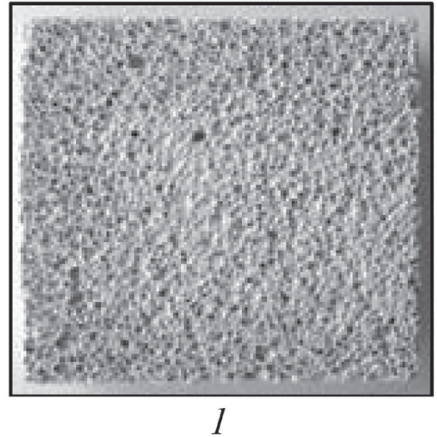

1

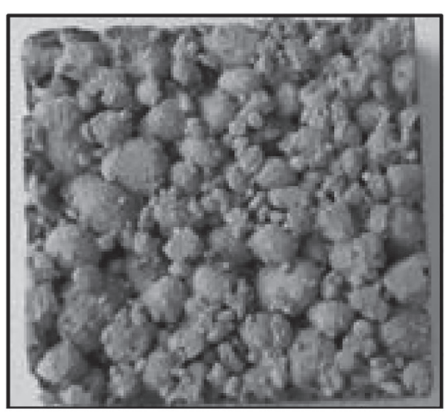

1

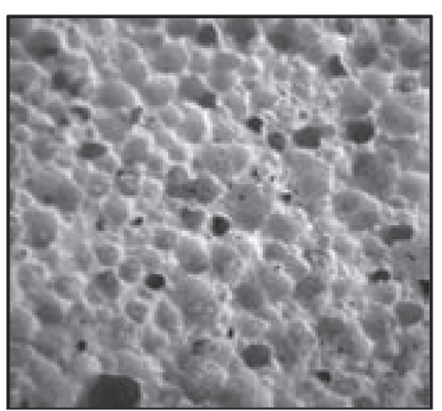

2

$a$

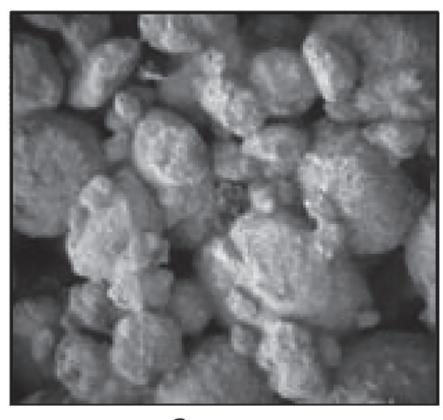

2

$b$

Рис. 1. Образцы строительных блоков (1 - внешний вид; 2 - под микроскопом) из газосиликата $(a)$

и керамзитобетона $(b)$

Fig. 1. Samples of building blocks ( 1 - appearance; 2 - under a microscope) from gas silicate $(a)$ and expanded clay concrete $(b)$ 
Испытание стойкости строительных блоков к плесневому поражению проводили путем модельного заражения материалов мицелием и спорами микроскопических грибов, выделенных из очагов биоповреждения строительных материалов на минеральной основе (штукатурка, бетон, фуга, минеральная вата и др.).

При заражении строительных блоков сложной ячеистой структуры грибным мицелием в качестве посевного материала использовали пеллеты 3-суточной глубинной культуры грибов Aspergillus niger и Penicillium chrysogenum. Колонизирующую способность оценивали по интенсивности роста колоний и появлению спороношения на пеллетах. За фунгицидный эффект считали полное ингибирование развития пеллет на материале и отсутствие их жизнеспособности после перенесения на питательную среду Чапека-Докса [9].

Инокуляцию спорами проводили путем опрыскивания материалов суспензией (концентрация (1-2)·1 $10^{6}$ спор/мл). В качестве тест-культур использовали микромицеты видов Alternaria alternata, Aspergillus niger, Chaetomium globosum, Paecilomyces variotii, Penicillium chrysogenum, Penicillium italicum, Trichoderma viride. Зараженные образцы помещали в чашки Петри и инкубировали при относительной влажности воздуха $80 \pm 5 \%$ и температуре $28{ }^{\circ} \mathrm{C}$. Для имитации внешнего загрязнения строительных блоков суспензию готовили в жидкой минеральной среде с $3 \%$ сахарозы.

Степень развития плесневых грибов на образцах, инокулированных спорами, оценивали спустя 28 сут в баллах согласно ГОСТ 9.048-89: 0 - под микроскопом прорастания спор не обнаружено; 1 - под микроскопом видны проросшие споры и незначительно развит мицелий; 2 - под микроскопом виден развитый мицелий, возможно спороношение; 3 - невооруженным глазом виден мицелий и (или) спороношение едва заметно, но отчетливо видно в микроскоп; 4 невооруженным глазом отчетливо просматривается развитие грибов, покрывающих не менее $25 \%$ испытуемой поверхности; 5 - невооруженным глазом хорошо заметно развитие грибов, покрывающих более 25 \% испытуемой поверхности [10].

Результаты и их обсуждение. Моделирование взаимодействия мицелия грибов A. niger и P. chrysogenum со строительными блоками показало, что при отсутствии дополнительного увлажнения керамзитобетонных блоков пеллеты тест-культур высыхают и утрачивают жизнеспособность уже на 3-и сутки инкубирования. Активного развития плесневых грибов на воздушно-сухих газосиликатных блоках не наблюдается, однако пеллеты покрываются спороношением, что способствует дальнейшему распространению грибных пропагул по воздуху (рис. 2).

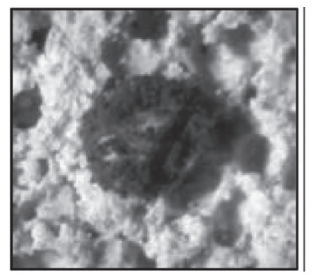

Спороношение $A$. niger

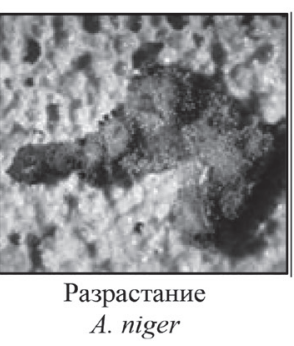

Воздуино-сухие строительные блоки

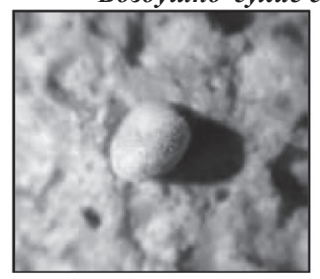

Спороношение P. chrysogenum

Влажные строительные блоки

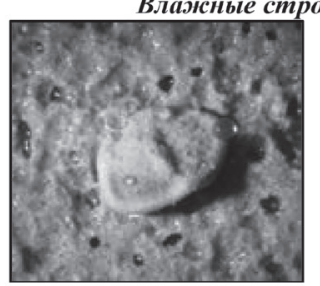

Спороношение P. chrysogenum

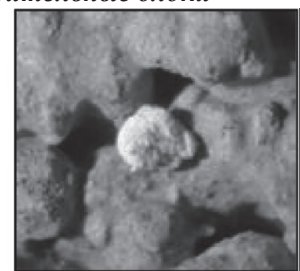

Высохшая пеллета A. niger

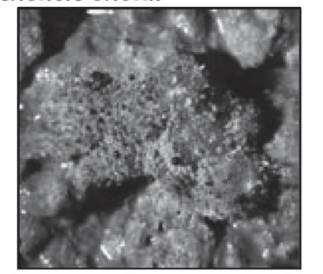

Разрастание A. niger

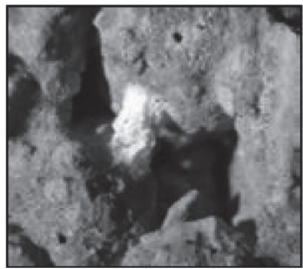

Высохшая пеллета P. chrysogenum

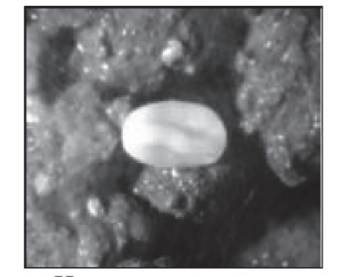

Интактная пеллета P. chrysogenum

b

Рис. 2. Состояние пеллет A. niger и P. chrysogenum спустя 21 сут инкубирования на газосиликатных (a) и керамзитобетонных $(b)$ блоках в сухом и увлажненном виде

Fig. 2. State of $A$. niger and $P$. chrysogenum pellets after 21 days of incubation on gas-silicate $(a)$ and claydite-concrete $(b)$ blocks in dry and wet form 
При повышении влажности газосиликата и керамзитобетона стойкость строительных блоков к колонизации плесневыми грибами снижается. Спустя 21 сут инкубирования пеллеты $A$. niger дают черное спороношение, сопровождающееся разрастанием колоний на обоих видах испытанных блоков. P. chrysogenum дает спороношение и экссудат только на пеллетах, помещенных на влажные газосиликатные блоки. На влажном керамзитобетоне пеллеты $P$. chrysogenum остаются интактными, не вызывая интенсивного поражения блоков, но сохраняя при этом свою жизнеспособность и биоповреждающий потенциал (рис. 2).

Испытание грибостойкости газосиликатных и керамзитобетонных блоков при заражении спорами показало, что на воздушно-сухих строительных материалах без органического загрязнения рост плесневых грибов A. alternata, A. niger, Ch. globosum, P. variotii, P. chrysogenum, P. italicum, T. viride полностью отсутствует (0 баллов). Внешнее загрязнение блоков может служить дополнительным источником питания для грибов и стимулировать прорастание спор и развитие мицелия. В присутствии органического загрязнения газосиликатные блоки подвергаются микробной колонизации (3 балла) даже в воздушно-сухом состоянии (см. таблицу).

Интенсивность развития плесневых грибов на газосиликатных и керамзитобетонных блоках спустя 28 сут после заражения спорами

Intensity of mould fungi development on gas silicate and claydite-concrete blocks on 28 day after inoculation with spores

\begin{tabular}{|l|l|c|c|}
\hline \multirow{2}{*}{$\begin{array}{c}\text { Строительные блоки } \\
\text { без органического загрязнения }\end{array}$} & \multicolumn{2}{|c|}{ Оценка грибостойкости, балл“ } \\
\cline { 2 - 3 } Газосиликатные & вез органического загрязнения & с органическим загрязнением \\
\cline { 2 - 4 } & влажушно-сухие & $0 ; 0 ; 0$ & $3 ; 3 ; 3$ \\
\hline \multirow{2}{*}{ Керамзитобетонные } & воздушно-сухие & $2 ; 2 ; 2$ & $4 ; 5 ; 5$ \\
\cline { 2 - 4 } & влажные & $0 ; 0 ; 0$ & $0 ; 0 ; 0$ \\
\hline
\end{tabular}

${ }^{*}$ ГOCT 9.048-89.

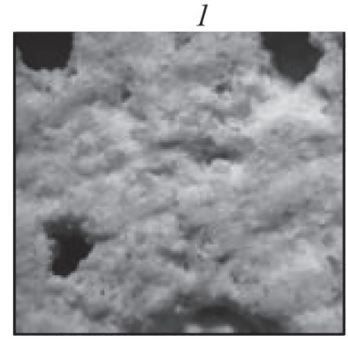

Мицелий виден под микроскопом

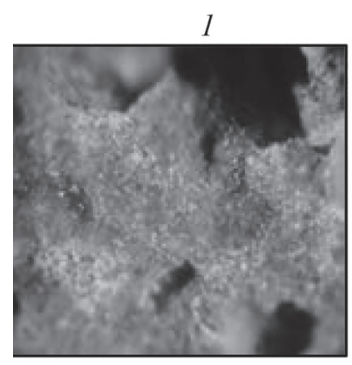

Незначительно развит мицелий

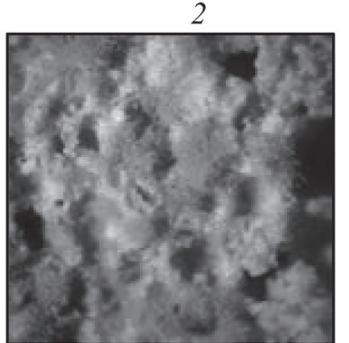

Спороношение видно невооруженным глазом

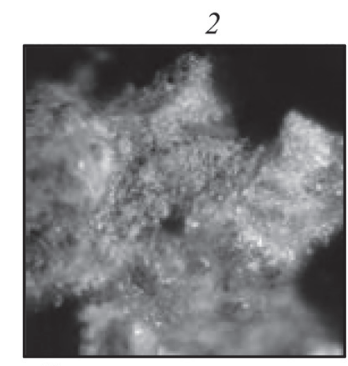

Спороношение видно под микроскопом

$b$

Рис. 3. Развитие плесневых грибов на влажных газосиликатных ( $a$ ) и керамзитобетонных $(b)$ блоках ( 1 - без органического загрязнения; 2 - с органическим загрязнением) спустя 28 сут после инокуляции спорами

Fig. 3. The development of mould fungi on wet gas silicate $(a)$ and claydite-concrete $(b)$ blocks ( 1 - without organic pollution; 2 - with organic pollution) on 28 day after inoculation with spores 
Спустя 28 сут после инокуляции загрязненной поверхности влажного газосиликата обильное спороношение микромицетов регистрируется невооруженным глазом (4-5 баллов). В тех же условиях на керамзитобетонных блоках обнаруживается очаговое развитие мицелия и слабое спороношение, заметное только под микроскопом (2-3 балла) (см. таблицу, рис. 3).

На сухих блоках из керамзитобетона споры не прорастают (0 баллов) даже при наличии органического загрязнения (см. таблицу).

Оценка влияния локального увлажнения строительных блоков на развитие плесневых грибов показала, что через 7 сут инкубирования агаровые диски со спорами A. niger на газосиликатных блоках покрываются мицелием с черным спороношением, на керамзитобетонных блоках высыхают и не дают развиться плесени (рис. 4). Вероятной причиной является то, что блоки из ячеистого бетона медленнее поглощают воду, но, обладая высокой влагоемкостью, долго удерживают влагу в порах, что способствует плесневому поражению. Гранулированная структура керамзитобетона обеспечивает более быстрое испарение влаги.
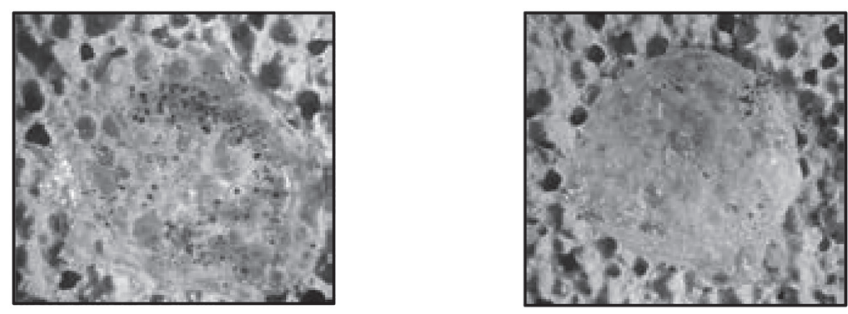

Спороношение $A$. niger
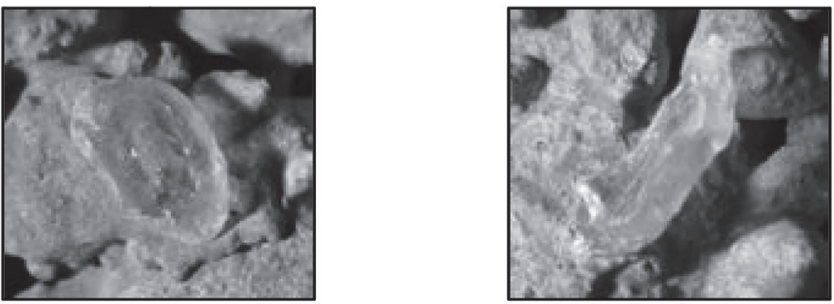

Отсутствие плесневого поражения

$b$

Рис. 4. Состояние агаровых дисков через 7 сут инкубирования на газосиликатных $(a)$ и керамзитобетонных $(b)$ блоках

Fig. 4. State of agar disks after 7 days of incubation on gas-silicate $(a)$ and claydite-concrete $(b)$ blocks

Заключение. В условиях модельного эксперимента установлено, что повреждающая активность мицелия грибов A. niger и P. chrysogenum по отношению к строительным блокам зависит от влажности материалов. При контакте с влажными газосиликатными и керамзитобетонными блоками мицелий A. niger обладает более высокой скоростью обрастания минерального субстрата, чем P. chrysogenum. Угнетение роста и утрата жизнеспособности мицелия обеих тест-культур возможна только при отсутствии увлажнения строительных блоков.

Помимо увлажнения на грибостойкость строительных блоков влияет наличие внешнего загрязнения, которое служит дополнительным источником питания для микромицетов. Органическое загрязнение газосиликата стимулирует прорастание спор и развитие мицелия даже при воздушно-сухом состоянии блоков.

Быстрое появление спороношения плесневых грибов при локальном увлажнении газосиликатных блоков может способствовать более интенсивной микробной колонизации при повторном намокании, а также повышает микологическую опасность для здоровья людей.

Таким образом, риск развития плесневых грибов на газосиликатных строительных блоках во влажной среде эксплуатации (конденсат, проливы, атмосферные осадки) выше, чем на керамзитобетонных блоках. В то же время профилактика плесневого поражения сооружений из ячеистого и керамзитобетона должна включать предотвращение избыточного увлажнения, а также загрязнения конструкций органическими и другими веществами, способствующими развитию биодеструкторов. 


\section{Список использованных источников}

1. Лихачев, А. Н. Колонизация микромицетами техногенных субстратов в зданиях / А. Н. Лихачев // Успехи мед. микологии. - 2004. - Т. 3. - С. 93-95.

2. Антонов, В. Б. Микозы и микогенная аллергия как антропогенно-очаговые заболевания / В. Б. Антонов // Успехи мед. микологии. - 2005. - Т. 5. - С. 54-56.

3. Марфенина, О. Е. Потенциально патогенные мицелиальные грибы в среде обитания человека. Современные тенденции / О. Е. Марфенина, Г. М. Фомичева // Микология сегодня. - 2007. - Т. 1. - С. 235-266.

4. Повреждения строительных материалов плесневыми грибами / Л. Ю. Огрель [и др.] // Экология и промышленность России. - 2000. - № 4. - С. 39-40.

5. Грибы-биодеструкторы, аллергены и патогены в жилых помещениях современной постройки / Е. В. Халдеева [и др.] // Проблемы мед. микологии. - 2011. - Т. 5, № 2. - С. 115.

6. Микромицеты в естественной среде обитания и в помещениях - их потенциальная опасность для здоровья людей / Е. В. Доршакова [и др.] // Проблемы мед. микологии. - 2012. - Т. 14, № 3. - С. 53-58.

7. Варченко, Е. А. Особенности оценки биоповреждений и биокоррозии материалов в природных средах / Е. А. Варченко // Политем. сетевой электрон. науч. журн. Кубан. гос. аграр. ун-та. - 2014. - № 104. - С. $1987-2004$.

8. Проблемы сохранения жилой и производственной инфраструктуры городов от биоразрушения / В. А. Крыленков [и др.] // Инфстрой. - 2003. - № 5. - С. 3-13.

9. Колонизация грибами рода Aspergillus текстильных материалов с наноструктурным металлическим покрытием / А. А. Арашкова [и др.] // Современная микология в России / Нац. акад. микологии. - М., 2015. - Т. 4 : Материалы III Междунар. микологического форума / гл. ред. Ю. Т. Дьяков. - С. 279-281.

10. Единая система защиты от коррозии и старения. Изделия технические. Методы лабораторных испытаний на стойкость к воздействию плесневых грибов : ГОСТ 9.048-89. - Введ. 01.07.91. - М. : Гос. комитет СССР по стандартам, 1989. -22 c.

\section{References}

1. Likhachev A. N. Colonization of technogenic substrates in buildings by micromycetes. Uspekhi meditsinskoi mikologii [Advances in medical mycology], 2004, vol. 3, pp. 93-95 (in Russian).

2. Antonov V. B. Mycoses and mycogenous allergy as anthropogenous diseases. Uspekhi meditsinskoi mikologii [Advances in medical mycology], 2005, vol. 5, pp. 54-56 (in Russian).

3. Marfenina O. E., Fomicheva G. M. Potentially pathogenic filamentous fungi in the human habitat. Modern tendencies. Mikologiya segodnya [Mycology today], 2007, vol. 1, pp. 235-266 (in Russian).

4. Ogrel' L. Yu., Pavlenko V. I., Glushchenko V. I., Prudnikova T. N. Damage of building materials by mould fungi. Ekologiya i promyshlennost' Rossii [Ecology and industry of Russia], 2000, no. 4, pp. 39-40 (in Russian).

5. Haldeeva E. V., Glushko N. I., Lisovskaya S. A., Parshakov V. R. Fungi-biodestructors, allergens and pathogens in residential buildings of modern construction. Problemy meditsinskoi mikologii [Problems of medical mycology], 2011, vol. 5, no. 2, p. 115 (in Russian).

6. Dorshakova E. V., Blinov N. P., Pavlova I. E., Bogomolova T. S., Chilina G. A., Vasil'eva N. V. Micromycetes in the natural habitat and indoors - their potential danger to human health. Problemy meditsinskoi mikologii [Problems of medical mycology], 2012, vol. 14, no. 3, pp. 53-58 (in Russian).

7. Varchenko E. A. Estimation of biodegradation and bio-corrosion of materials in natural environments. Politematicheskii setevoi elektronnyi nauchnyi zhurnal Kubanskogo gosudarstvennogo agrarnogo universiteta [Polythematic network electronic scientific journal of the Kuban State Agrarian University], 2014, no. 104, pp. 1987-2004 (in Russian).

8. Krylenkov A., Vlasov D. Yu., Dashko R. E., Startsev S. A. Problems of preserving the residential and industrial infrastructure of cities from bioremediation. Infstroi [Infstroy], 2003, no. 5, pp. 3-13 (in Russian).

9. Arashkova A. A., Goncharova I. A., Kostenevich A. A., Pobol' I. L., Denizhenko A. G., Mochailo E. V., Kokhnyuk V. N. Colonization by fungi of the genus Aspergillus of textile materials with nanostructural metal coating. Modern mycology in Russia. Vol. 4. Materials of the III International Mycological Forum. Moscow, 2015, pp. 279-281 (in Russian).

10. State Standard 9.048-89. Unified system of protection against corrosion and aging. Technical products. Methods of laboratory tests for resistance to mould fungi. Moscow, Publishing House for Standards, 1989. 22 p. (in Russian).

\section{Информация об авторе}

Арашкова Алина Александровна - науч. сотрудник. Институт микробиологии НАН Беларуси (ул. Акад. Купревича, 2, 220141, г. Минск, Республика Беларусь). E-mail: arashkova.mycology.by@gmail.com

\section{Information about the author}

Alina A. Arashkova - Researcher. Institute of Microbiology of the National Academy of Sciences of Belarus (2, Kuprevich Str., 220141, Minsk, Republic of Belarus). E-mail: arashkova.mycology.by@gmail.com 